\title{
Bladder Stones Associated with an Aggressive Plasmacytoid Variant of Urothelial Cancer: A Rare Case and Literature Review
}

\author{
Mohammed Alsheikh* Mohammad Faruquz Zaman* Preethi Gopinath* \\ Ahmed Qteishat ${ }^{*}$ \\ Department of Urology, Princes Alexandra Hospital, Harlow, UK \\ "These authors contributed equally to the manuscript.
}

\author{
Key Words \\ Bladder cancer • Squamous cell carcinoma of bladder • \\ Bladder stones
}

\begin{abstract}
Urothelial carcinoma is the most common histologic subtype of bladder cancer, accounting for approximately $90 \%$. We herein report a case of a 78-year-old man with an unusual association of bladder stones with an aggressive plasmacytoid variant of urothelial cancer. Initially he presented in 2009 with a very large bladder stone and was treated by an open cystolithotomy. Histology from a bladder biopsy at that time was benign. He failed to attend follow-up appointments but subsequently he attended in 2016 with a recurrent urinary tract infection and an acute kidney injury. A CT scan showed multiple bladder stones. The cause of our patients' multiple bladder stones is unclear and unusual. He then underwent a further open cystolithotomy according to our multidisciplinary team recommendation. Post-operatively he unfortunately developed a non-healing vesicocutaneous fistula for which he was performed cystoscopy and biopsy but ended with transurethral resection due to the extent of abnormal/ necrotic tissue. Histology confirmed a plasmacytoid variant
\end{abstract}

\section{KARGER}

Fax +4161306 1234

E-Mail karger@karger.com

www.karger.com
(C) 2020 The Author(s)

Published by S. Karger AG, Basel Upen access

This article is licensed under the Creative Commons AttributionNonCommercial-NoDerivatives 4.0 International License (CC BYNC-ND) (http://www.karger.com/Services/OpenAccessLicense) Usage and distribution for commercial purposes as well as any distribution of modified material requires written permission. of urothelial cancer. To our knowledge, this is the first case of an association of bladder stones with a plasmacytoid variant of urothelial cancer.

(C) 2020 The Author(s)

Published by S. Karger AG, Basel

\section{Introduction}

Bladder cancer is the 11th most common cancer worldwide, with an incident of 429,793 (3.1\%) cases and a mortality of $165,084(2 \%)$ persons [1]. Urothelial carcinoma is the most common in which around $90 \%$ cases are transitional cell carcinoma. The urothelium consists of transitional epithelium with the ability to undergo metaplasia [3] and glandular differentiation [4] under certain circumstances. In recent years, new distinct and uncommon variants of urothelial carcinoma have been described. Association of squamous cell carcinoma (SCC) and bladder stones is well established. However, bladder stones with a plasmacytoid variant of urothelial carcinoma (PUC) has never been described. We herein present and report a rare case of recurrent bladder stones associated with a PUC. 


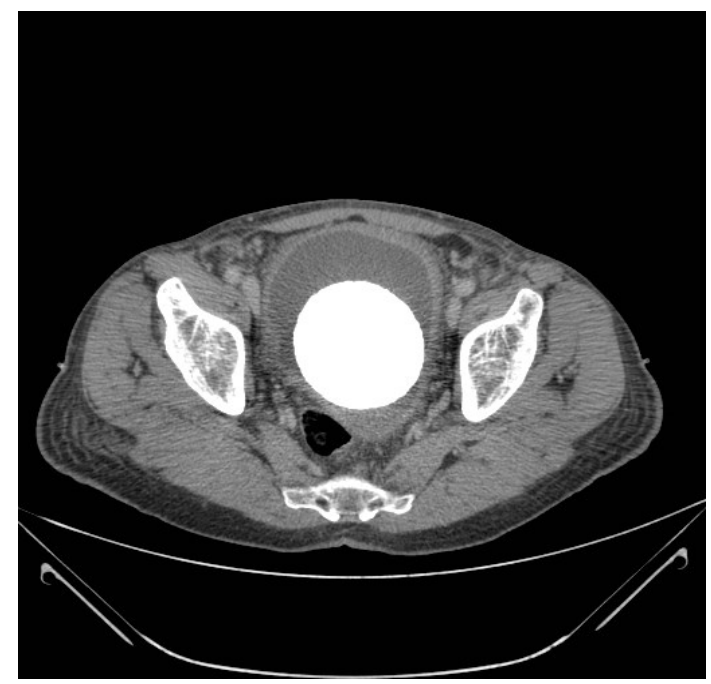

Fig. 1. Axial CT imaging (2009) showed a large single bladder stone with a thick walled bladder and a possible soft tissue mass surrounding the stone.

Bladder calculi are predominantly a disease of men aged above 50 with bladder outflow obstruction and benign enlargement of prostate. They also occur in chronically catheterized patients (such as spinal cord injury) where the chance of developing bladder stones is $25 \%$ over 5 years [5]. SCC represents the most common non -urothelial bladder malignancy, accounting for $2-5 \%$ of cases in most contemporary cystectomy series [6-10]. These tumors are most often diagnosed during the seventh decade of life. The condition is believed to arise as a result of chronic urinary tract inflammation, a factor that may contribute to the higher likelihood of SCC in patients with chronic cystitis, persistent bladder stones and diverticula [11].

\section{Case Report}

\section{Clinical Data}

A 78-year-old man presented to us initially in 2009 with an acute kidney injury (AKI), hematuria and mild lower urinary tract symptoms (LUTS). He gave a history of weight loss, lethargy and anorexia. Laboratory investigations showed a creatinine $255 \mu \mathrm{mol} / \mathrm{l}$, eGFR $22 \mathrm{ml} / \mathrm{min}$ and CRP $100 \mathrm{mg} / \mathrm{l}$. Urine was positive for coliform. An ultrasound scan of urinary tract showed bilateral hydronephrosis with a large bladder stone. Subsequent CT confirmed large bladder stone, bilateral hydronephrosis, and very thickened bladder wall - suspicious of bladder tumor (fig. 1). Bilateral nephrostomy tubes were inserted. Urine cytology did not show any malignant cells. Rigid cystoscopy showed a very

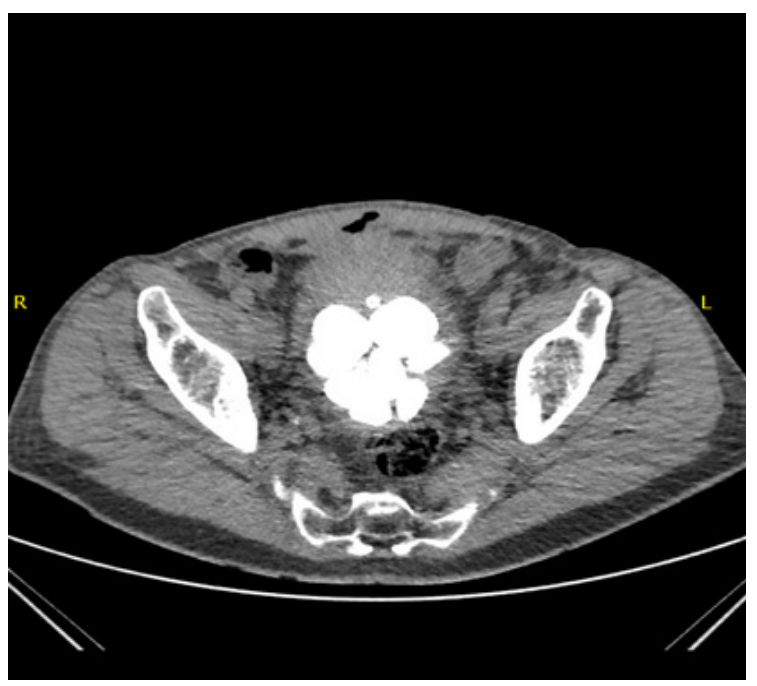

Fig. 2. Multiple bladder stones with a thickened bladder wall (prior to cystolithotomy).

large of bladder stone and the surgeon was unable to look into the whole bladder because of the size of stone. The both ureteric orifices were not identified. The case was then discussed at our multidisciplinary team meeting and the recommendation was for a percutaneous ultrasound guided bladder biopsy prior to consideration of an open cystolithotomy. Histology of the percutaneous biopsies showed severe chronic cystitis and cystitic glandularis. Subsequently, he underwent open cystolithotomy. He recovered well apart from delayed wound healing. His kidney function returned to normal and the nephrostomy tubes were removed. Multiple bladder biopsies during the open cystolithotomy did not show evidence of dysplasia or malignancy. He was discharged home with a follow-up appointment. Unfortunately, he did not attend his subsequent clinic appointments and he was lost to follow-up from 2009 until 2016.

He presented 7 years later with similar symptoms of LUTS, an AKI and abdominal pain. His blood tests revealed a creatinine of $297 \mu \mathrm{mol} / \mathrm{l}$, eGRF $18 \mathrm{ml} / \mathrm{min}, \mathrm{Hb} 123 \mathrm{~g} / \mathrm{l}$, WBC $29.3 \times 10^{9} / \mathrm{l}$ and CRP $188 \mathrm{mg} / \mathrm{l}$. An ultrasound scan of urinary tract showed numerous bladder stones with bilateral hydronephrosis. A CT confirmed multiple bladder stones (fig. 2), the largest one is $4.8 \mathrm{~cm}$ with left sided hydronephrosis and a hydroureter down to the vesicoureteric junction. The patient was scheduled for an open cystolithotomy according to our multidisciplinary team recommendation. During the operation 14 stones were removed from the bladder, the largest stone was $4.6 \mathrm{~cm}$ in size. He had a complicated postoperative recovery as he developed a vesicocutaneous fistula after removal of his abdominal drain. A urethral catheter was left in-situ for almost 6 weeks. Subsequently, the fistula sealed off. However, he was re-admitted within a couple of months' time with an AKI, gross hematuria and clot retention. A CT scan showed bilateral hydronephrosis and a large soft tissue mass or a possible organized hematoma at the anterior wall of bladder and an extravesical soft tissue mass involving the abdominal wall (fig. 3, 4). 


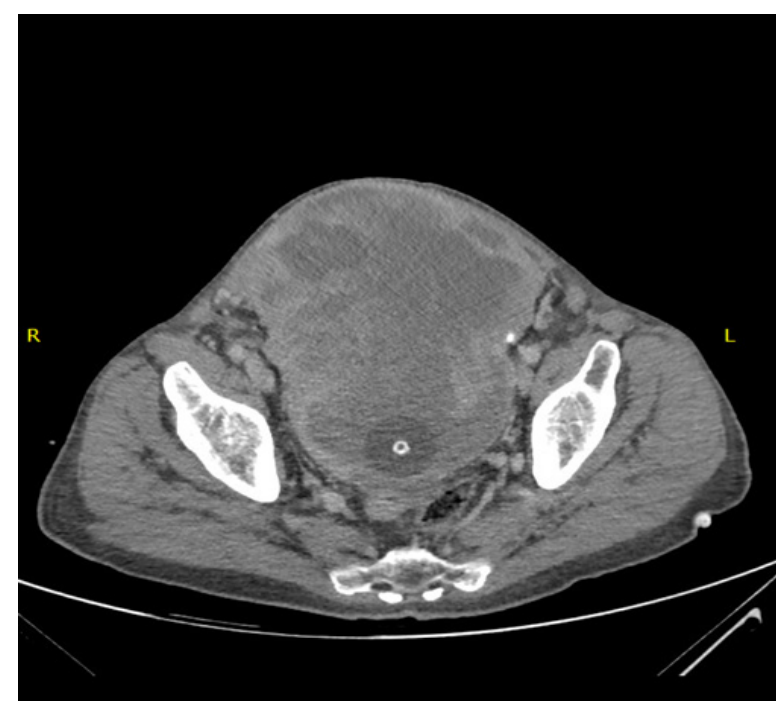

Fig. 3. Axial view of the bladder mass with extravesical involvement (after cystolithotomy).

A transurethral resection was performed for almost 2 hours and resected chips looked like organized hematoma or necrotic tissue. The ureteric orifices were not identified therefore the surgeon was unable to insert retrograde ureteric stents. Total $130 \mathrm{~g}$ of resected tissue was sent for histology. He then underwent bilateral nephrostomies by the interventional radiology and subsequently his kidney function improved.

\section{Histological Evaluation}

The resected specimen was comprised of blood and fragments of necrotic tumor. The tumor was composed of sheets of highly atypical and pleomorphic cells with increased nuclear to cytoplasmic ratios, irregular nuclear membranes, prominent nucleoli and eosinophilic to vacuolated cytoplasm (fig. 5). Mitotic activity was conspicuous. In areas, the tumor had a pseudovascular pattern and there was admixed mucin. Within the specimen there were also fragments of hyperkeratotic, parakeratotic and dysplastic squamous epithelium, with adjacent cords of atypical squamous cells with an infiltrative pattern.

\section{Immunohistochemistry}

The majority of the tumor cells were positive for CD138 and cyclin D1 (fig. 6, 7), with weak staining for CD117 and weaker staining for epithelial membrane antigen. There was no $\kappa$ or $\lambda$ light chain restriction. MNF116, CKAE1/3, CK7, CK20, TTF-1, PSA, CK5/6, P63, CD45, S100, CD56 and CD20 were negative. The proliferation index in the atypical cells by Ki-67 immunohistochemistry was approximately 60-70\%. Overall, and considering the background mucin and squamous dysplasia, the appearances favored those of high grade (Grade 3) solid urothelial carcinoma of a plasmacytoid type with focal squamous, sarcomatoid and glandular differentiation.

Bladder Stones with Plasmacytoid Variant of Urothelial Cancer

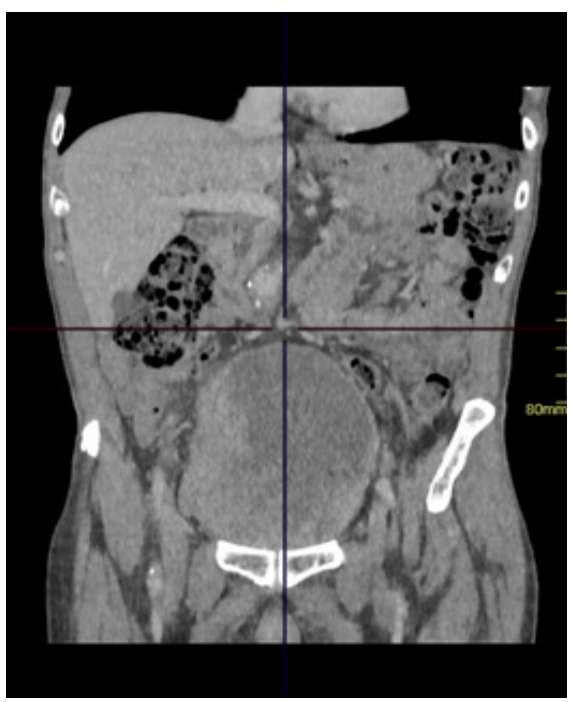

Fig. 4. Coronal view of the bladder tumor extension (after cystolithotomy).

\section{Treatment}

The patient had lost a significant amount of weight, developed anorexia and became cachectic within weeks of diagnosis. A staging CT showed lung metastasis. But sadly, the patient became fatigued, cachectic, developed pneumonia and his condition deteriorated rapidly and finally he passed away prior to receiving the scheduled chemotherapy.

\section{Discussion}

Bladder cancer is the most common malignancy of the urinary tract. Urothelial carcinoma is the most common histologic type of bladder cancer in the United States, accounting for approximately $90 \%$. Nonurothelial bladder cancers are less common. SCC accounts for $2-5 \%$ of all bladder cancers.

In some parts of the world, infection with Schistosoma haematobium is prevalent, SCC is the most common bladder cancer, responsible for approximately $50 \%$ of all bladder cancers [12]. In North America, however, SCC is less common, making up only $3-5 \%$ of bladder cancers [10]. PUC is rare and only recently included in the current WHO classification of urothelial neoplasm. We here present a case of PUC in a male associated with multiple bladder stones. To our knowledge this is the first case of PUC associated with bladder stones. 


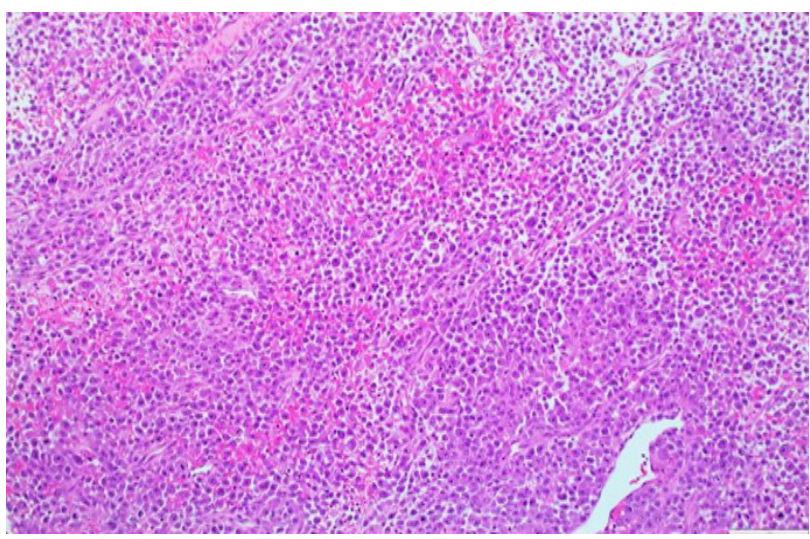

Fig. 5. H\&E showing plasmacytoid urothelial carcinoma variant $(\times 10)$.

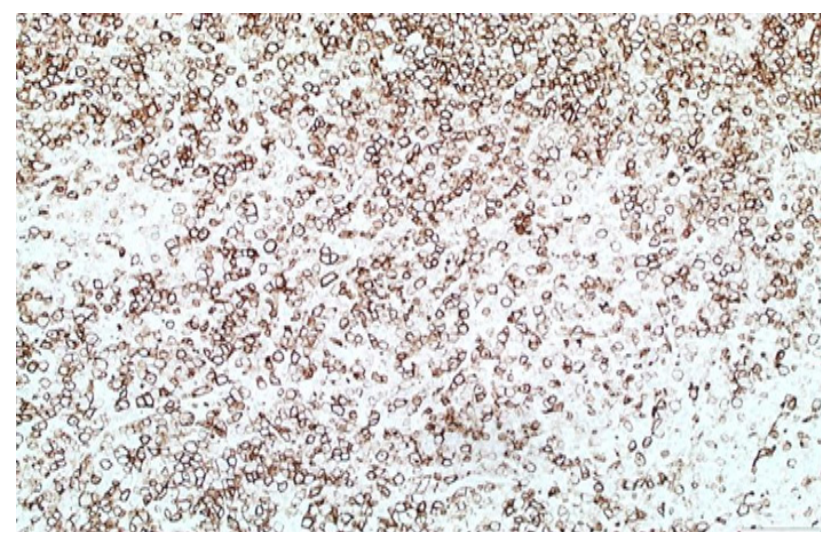

Fig. 6. CD138 staining showing diffuse membranous positivity in plasmacytoid areas $(\times 10)$.

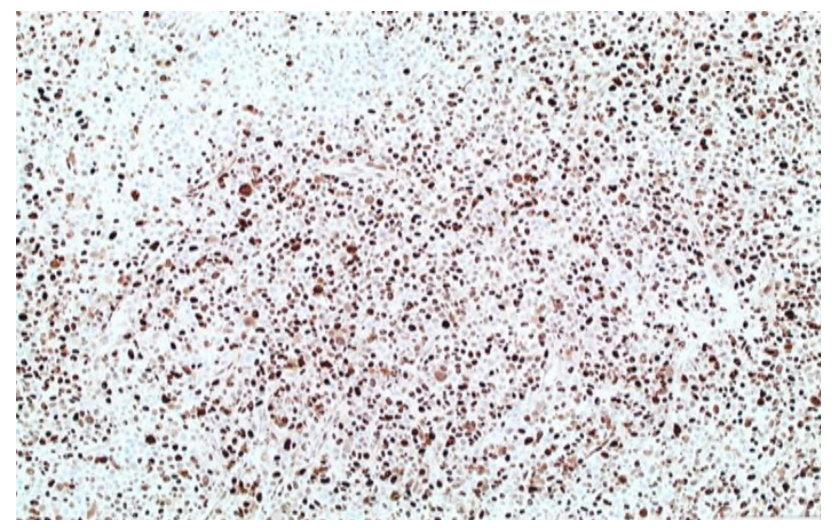

Fig. 7. Cyclin D1 nuclear positivity in plasmacytoid areas $(\times 10)$.
The cause of our patient's multiple bladder stones is unclear and unusual. However, we expect SCC to be attributed to bladder stone formers. The association between chronic bladder irritation and SCC has been well established [13, 14]. Chronic bladder irritation includes chronic or recurrent urinary tract infection, chronic indwelling urinary catheters, bladder calculi, foreign bodies, intravesical Bacillus Calmette-Guerin and prolonged exposure to cyclophosphamide [15]. A 2-fold increase in bladder cancer risk was observed with a history of bladder stones in a case-control study [16]. Several studies also showed a positive association between kidney or ureteral stones and the risk of bladder cancer $[17,18]$. Longstanding bladder stones have been implicated as a cause of SCC of the bladder via chronic mucosal injury with resulting inflammation and disruption of the protective glycosaminoglycan layer [19]. The 2- and 5-year overall survival rates have been reported as 47.6 and $10.6 \%$ respectively from M.D. Anderson Cancer Center [20]. Radical cystectomy remains the mainstay of therapy in selected patients with resectable disease. Chemotherapy and radiation therapy can be considered in patients who are not surgical candidates or patients with metastasis.

PUC is a rare aggressive variant seen in elderly patients. The most common presenting symptoms are hematuria, usually accompanied by urgency, frequency and/or lower abdominal pain. Clinical management of PUC remains debatable because of its rarity. One study reported that $33 \%$ of PUC presented with intraperitoneal disease and $20 \%$ had subsequent metastasis involving serosal surfaces. Furthermore, the possibility of non-contiguous intraperitoneal spread involving serosal surfaces has been reported [21]. The architectural patterns of PUC may vary. The cells may present in cords with single cells, small nests, solid sheet-like or diffuse discohesive patternless arrangements [22]. Dayyani et al. [23] found that the most common site of PUC recurrence was the peritoneum. Thus peritoneal carcinomatosis should be considered in patients presenting with abdominal symptoms. Rice et al. [24] suggested that the plasmacytoid variant of urothelial cancer might be a marker for locally advanced and aggressive disease rather than superficially influencing lymphatic spread.

Immunohistochemical staining plays an important role in the diagnosis of PUC. An appropriate panel of antibodies for immunophenotyping of the atypical neoplastic cells comprises epithelial membrane antigen and cytokeratins (CKs) including AE1/AE3, CAM5.2, CK7, CK8, CK10, CK18, CK19, and CK20. CD138, a marker for plasma cells, is positive in both plasmacytoma and 
Table 1. Treatment and clinicopathological features [27]

\begin{tabular}{|c|c|c|c|c|}
\hline Method of treatment & Total number & Presentation/number of patient & TNM stage/ number & Follow-up status \\
\hline $\begin{array}{l}\text { Radical cystectomy + } \\
\text { chemotherapy }\end{array}$ & 13 & $\begin{array}{l}\text { hematuria: } \mathrm{n}=5 \\
\text { hematuria + hydronephrosis: } \mathrm{n}=2 \\
\text { hematuria + dysuria/frequency: } \mathrm{n}=1 \\
\text { pollakiuria: } \mathrm{n}=1 \\
\text { painful micturition: } \mathrm{n}=1 \\
\text { nocturia + pencil like stool: } \mathrm{n}=1\end{array}$ & $\begin{array}{l}\text { T3: } n=8 \\
\text { T4: } n=5\end{array}$ & survive $4-36$ months \\
\hline TURBT + chemotherapy & 21 & $\begin{array}{l}\text { hematuria: } n=16 \\
\text { hematuria + LUTS: } n=4 \\
\text { N/A: } n=1\end{array}$ & $\begin{array}{l}\text { T1: } \mathrm{n}=1 \\
\text { T2: } \mathrm{n}=2 \\
\text { T3: } \mathrm{n}=12 \\
\text { T4: } \mathrm{n}=4 \\
\text { N/A: } \mathrm{n}=2\end{array}$ & survive $4-24$ months \\
\hline $\begin{array}{l}\text { Radical cystoprostatec- } \\
\text { tomy } \pm \text { chemotherapy }\end{array}$ & 7 & $\begin{array}{l}\text { hematuria: } \mathrm{n}=5 \\
\text { urinary urgency: } \mathrm{n}=1 \\
\text { N/A: } \mathrm{n}=1\end{array}$ & $\begin{array}{l}T 4: n=2 \\
\text { T3: } n=4 \\
\text { T1: } n=1\end{array}$ & $\begin{array}{l}\text { survive } 2 \text { weeks to } 43 \\
\text { months; one alive } 16 \\
\text { months }\end{array}$ \\
\hline Chemotherapy & 2 & $\begin{array}{l}\text { hematuria + LUTS: } n=1 \\
\text { N/A: } n=1\end{array}$ & $\begin{array}{l}\text { ND: } \mathrm{n}=1 \\
\text { T3: } \mathrm{n}=1\end{array}$ & survive $20-24$ months \\
\hline $\begin{array}{l}\text { No treatment (biopsy } \\
\text { only) }\end{array}$ & 4 & $\begin{array}{l}\text { hematuria: } n=3 \\
\text { hematuria + back pain: } n=1\end{array}$ & $\begin{array}{l}\text { T1: } \mathrm{n}=1 \\
\text { ND: } \mathrm{n}=1 \\
\text { T3: } \mathrm{n}=1 \\
\text { T4: } \mathrm{n}=1\end{array}$ & $\begin{array}{l}\text { survive } 7 \text { days to } 4 \\
\text { months; one alive } 4 \\
\text { months }\end{array}$ \\
\hline BCG Rx (treatment) only & 1 & hematuria: $\mathrm{n}=1$ & $\mathrm{~T} 1: \mathrm{n}=1$ & alive 47 months \\
\hline
\end{tabular}

TURP $=$ Transurethral resection of prostate $; \mathrm{BCG}=$ bacillus calmette guerin $; \mathrm{Rx}=$ treatment N $/ \mathrm{A}=$ not available $;$ ND $=$ not determined.

PUC and $\kappa$ and $\lambda$ light chains are used to differentiate between the 2 lesions. PUC is positive for CD138 but negative for light chains as seen in our case. It has been noted that loss of E-cadherin expression might be associated with a plasmacytoid differentiation pattern in urothelial cancer and is probably associated with increased cellular invasiveness or correlated with muscularis mucosal involvement and tumor recurrence. Mitsogiannis et al. [25] recently reported that plasmacytoid tumor cells were immunoreactive for CD138 in the bladder. Furthermore, Shimada et al. [26] reported the first case of urothelial carcinoma with a plasmacytoid variant expressing both CA19-9 and $\beta$-HCG. Therefore, tumor cells positive for CD138 (a marker of plasma cell origin) provides the evidence to support the diagnosis of PUC. In line with this assumption, immunohistochemical staining of tumor sections from our case revealed positive results for CD138. Recently GATA3 (endothelial transcription fac-

Bladder Stones with Plasmacytoid Variant of Urothelial Cancer tor 3) has been shown of value in urothelial cancer including PUC. GATA3 is useful in the recognition of the urothelial lineage of PUC in metastatic settings. We also detected positive staining for GATA3, p63, 34betaE12, CK14, CK5 and negative for CAM5.2, CK7, CK20. These results actually provided pivotal information for the final diagnosis of PUC.

There are no clear guidelines for the treatment of PUC. Table 1 [27] summarizes the possible treatment options of PUC depending on grading and staging of the tumor. To date, radical cystectomy is considered as the first line choice for both invasive and non-invasive PUC. However, both neoadjuvant and adjuvant treatment should be considered to reduce the risk progression of PUC. Patients with lymphovascular or nodal involvement and invasive tumors showed a moderate benefit from adjuvant combination chemotherapy, which includes 3 to 5 courses of MVAC chemotherapy. PUC is sensitive to both chemo- 
therapy and radiotherapy, which can be performed as adjuvant treatments after radical cystectomy. Kohno et al. [28] reported a case of PUC, which showed a complete response with 2 courses of neoadjuvant MVAC chemotherapy.

\section{Conclusion}

The PUC represents an aggressive rare tumor. Association of this tumor with bladder stones has never been described. Awareness of this variant when dealing with urogenital tract carcinoma is important in order to avoid a misdiagnosis. Histopathological diagnosis can be difficult at times, potentially leading to delayed or misdiagnosis. Immunohistochemistry is a valuable diagnostic tool and diagnosis can be achieved based on the immunohistochemistry result. A diagnosis of PUC usually carries a dismal prognosis. Hence, recognition of this rare variant by the pathologist is necessary for appropriate treatment to be instituted.

The association between foreign bodies in the bladder and SCC is well established. Our patient's unusual presentation with multiple bladder stones and a PUC of the bladder highlights the possible association between these two conditions. There are no guidelines for the treatment of PUC and therefore clinical management remains debatable. To date, limited available data suggests PUC is an aggressive high-grade tumor with poor prognosis. Larger cohorts are needed for the development of effective strategies for the management of this devastating disease.

\section{References}

1 World Health Organization. GLOBOCAN 2012: Estimated cancer incidence, mortality and prevalence worldwide 2012 (Accessed on Nov 2014).

2 Bostwick DG, Cheng L: Urologic surgical pathology, ed 2. Mosby, Elsevier, 2008, pp272-299.

-3 Baldwin L, Lee AH, Al-Talib RK, Theaker JM: Transitional cell carcinoma of the mimicking lobular carcinoma of the breast: a discohesive variant of urothelial carcinoma. Histopathology 2005;46:50-56.

4 Nigwekar P, Amin MB: The many faces of urothelial carcinoma: an update with an emphasis on recently described variants. Adv Anat Pathol 2008;15:218-233.

5 Ord J, Lunn D, Reynard J: Bladder management and the risk of bladder stone formation in spinal cord injured patient. J Urol 2003; 170:1734-1737.

6 Miller A, Mitchell JP, Brown NJ: The Bristol Bladder Tumour Registry: Br J Urol 1969;41(suppl):1-64.

7 Johnson DE, Schoenwald MB, Ayala AG, Miller LS: Squamous cell carcinoma of bladder. J Urol 1976;115:542-544.

8 Rundle JS, Hart AJ, McGeorge A, McVie JG, Calman KC: Squamous cell carcinoma of bladder: a review of 114 patients. Br J Urol 1982;54:522-526.

9 Lopez JI, Angulo Cuesta J, Flores Corral N, Toledo JD: Squamous cell carcinoma of the urinary bladder: clinic-pathologic study of 7 cases. Arch Esp Urol 1994;47:756-760.
10 Serretta V, Pomara G, Piazza F, Gange E: Pure squamous cell carcinoma of the bladder in western countries. Eur Urol 2000;37:85-89.

11 Cohen SM, Shirai T, Steineck G: Epidemiology and etiology of premalignant and malignant urothelial changes. Scand J Urol Nephrol Suppl 2000;205:105-115.

12 Jemal A, Bray F, Center MM, Ferlay J, Ward E, Forman D: Global cancer statistics. CA Cancer J Clin 2011;61:69-90.

13 Delnay KM, Stonehill WH, Goldman H, Jukkola AF, Dmochowski RR: Bladder histological changes associated with chronic indwelling urinary catheter. J Urol 1999; 161:1106-1108.

14 Michaud DS: Chronic inflammation and bladder cancer. Urol Oncol 2007;25:260-268.

15 Dahm P, Gschwend JE: Malignant non -urothelial neoplasm of the urinary bladder: a review. Eur Urol 2003;44:672-681.

16 Kantor AF Hartge P, Hoover RN, Narayana AS, Sullivan JW, Fraumeni JF Jr: Urinary tract infection and risk of bladder cancer. Am J Epidemiol 1984;119:510-515.

-17 Kjaer SK, Knudsen JB, Sorensen BL, Moller Jensen O: The Copenhagen case-control study on bladder cancer. V. Review of the role of urinary-tract infection. Acta Oncol 1989; 28:631-636.

18 Gonzalez CA, Errezola M, Izarzugaza I, Lopez-Abente G, Escolar A, Nebot M, Riboli E: Urinary retention, renal lithiasis and bladder cancer in Spain. Eur J Cancer 1991; 27:498-500.
19 Haddad FS, Chinichian A: Postprostatectomy lithiasis. Urol Int 1991;46:221-231.

20 Kassouf W, Spiess PE, Siefker-Radtke A, Swanson D, Grossman HD, Kamat AM, Munsell MF, Guo CC, Czerniak BA, Dinney $\mathrm{CP}$ : Outcome and patterns of recurrence of non-bilharzial pure squamous cell carcinoma of the bladder: a contemporary review of the University of Texas MD Anderson Cancer center. Cancer 2007;110:764-769.

21 Ricardo-Gonzalez RR, Nguyen M, Gokden N, Sangoi AR, Presti JC Jr, McKenney JK: Plasmacytoid carcinoma of the bladder: a urothelial carcinoma variant with a predilection for intraperitoneal spread. J Urol 2012; 187:852-855.

-22 Nigwekar P, Tamboli P, Amin MB, Osunkoya AO, Ben-Dor D, Amin MB: Plasmacytoid urothelial carcinoma: detailed analysis of morphology with clinicopathologic correlation in 17 cases. Am J Surg Pathol 2009: 33:417-424.

23 Dayyani F, Czerniak BA, Sircar K, Munsell MF, Millikan RE, Dinney CP, Siefker-Radtke AO: Plasmacytoid urothelial carcinoma, a chemosensitive cancer with poor prognosis, and peritoneal carcinomatosis. J Urol 2013; 189:1656-1661.

24 Rice KR, Koch MO, Kao CS, Pedrosa JA, Kaimakliotis HZ, Masterson TA, Bihrle R, Cheng L: Lymph node metastasis in patients with urothelial carcinoma variant: influence of the specific variant on nodal histology. Urol Oncol 2015;33:20.e23-20.e29. 
25 Mitsogiannis IC, Ioannou MG, Sinani CD, Melekos MD: Plasmacytoid transitional cell carcinoma of the urinary bladder. Urology 2005;66:194.

-26 Shimada K, Nakamura M, Ishida E, Konishi $\mathrm{N}$ : Urothelial carcinoma with plasmacytoid variants producing both human chorionic gonadotropin and carbohydrate antigen 19-9. Urology 2006;68:891.e7-10.
27 Wang Z, Lu T, Du L, Hu Z, Zhuang Q, Li Y, Wang CY, Zhu H, Ye Z: Plasmacytoid urothelial carcinoma of urinary bladder: a clinical pathological study and literature review. Int J Clin Exp Pathol 2012;5:601-608.
28 Kohno T, Kitamura M, Akai H, Takaha M, Kawahara K, Oka T: Plasmacytoid urothelial carcinoma of the bladder. Int $\mathrm{J}$ Urol 2006;13:485-486. 